\title{
Solvolysis of p-Nitrophenyl Esters Catalyzed by Oligo-4(5)-vinylimidazoles
}

\author{
C. G. Ovfreberghr and Chah-Moh Shen ${ }^{1}$ \\ Department of Chemistry and the Macromolecular Research Center, \\ The University of Michigan, Ann Arbor, Michigan 48104
}

Received January 18, 1971; accepted March 8, 1971

\begin{abstract}
The preparation of low molecular weight poly-4(5)-vinylimidazole is described. Oligomer fractions with molecular weight ranges from a few hundred to two thousand, five hundred were obtained by fractionation through a Sephadex LH-20 column. The apparent dissociation constant of the imidazolium ion in oligo-4(5)vinylimidazole decreases rapidly as the average molecular weight increases from 390 to 626 . At an average molecular weight greater than 626 , the apparent dissociation-constant value plateaus. The imidazole group in oligo-4(5)-vinylimidazole with ca. 5 imidazole units per oligomer molecule shows $71 \%$ of the solvolytic rate of the imidazole groups which are located in the oligomer with an average molecular weight of 2460 during the solvolysis of $p$-nitrophenyl acetate. The results indicate that short-range imidazole groups are interacting with each other to catalyze the solvolysis of $p$-nitrophenyl acetate. Solvolysis of $p$-nitrophenyl heptanoate catalyzed by oligomer fractions in $21 \%(\mathrm{v} / \mathrm{v}) n$-propanol-water solutions indicates that the solvolysis rate of $p$-nitrophenyl heptanoate increases with an increase of oligomer's molecular weight.
\end{abstract}

\section{INTRODUCTION}

The catalytic solvolysis of $p$-nitrophenyl acetate (PNPA) by poly-4(5)-vinylimidazole has been studied in $28.5 \%$ ethanol-water $(l)$ and a $10 \%$ methanol-water solution (2) at a $\mathrm{pH}$ range of 7-9. In both cases, the $k_{\text {eat }}$ vs. $\alpha_{1}$ (fraction of neutral imidazole on the polymer) profile showed an upward curvature. The total polymeric imidazole catalytic rate constant $\left(k_{\text {cat }}\right)$ can be expressed by Eq. (1) (2) where $k_{1}$ is a simple nucleophilic

$$
k_{\text {cat }}=k_{1} \alpha_{1}+k_{2} \alpha_{1}^{2}+k_{3} \alpha_{2}+k_{4} \alpha_{1} \alpha_{2}
$$

catalysis rate constant, $k_{2}$ is an imidazole-catalyzed imidazole nucleophilic catalysis rate constant, $k_{3}$ is a catalysis rate for imidazole anion, $k_{4}$ is a rate constant for anionic imidazole-catalyzed imidazole nucleophilic catalysis; $\alpha_{1}$ and $\alpha_{2}$ are fractions of neutral and anionic imidazole, respectively. Because the dissociation constant of poly-4(5)vinylimidazole $\left(\mathrm{p} K_{2}\right)$ is too high (estimated to be $\left.>14.5(3)\right)$ to allow an appreciable imidazole anion concentration to be present in the solution in the $\mathrm{pH}$ range previously used ( $\mathrm{pH} 7-9), \alpha_{2}$ is very small. The terms containing $\alpha_{2}$ can, therefore, he minimized. The rate equation for the solvolysis of PNPA catalyzed by poly-4(5)-vinylimidazole at a $\mathrm{pH}$ range of 7-9 can, therefore, be simplified to

$$
k_{\text {cat }}=k_{1} \alpha_{1}+k_{2} \alpha_{1}^{2}
$$

${ }^{1}$ Submitted in partial fulfillment of the requirements for the Ph.D. degree in Chemistry at The University of Michigan, 1970. 
The existence of bifunctional neutral-neutral imidazole interaction was indicated by a marked decrease in enthalpy and entropy of activation $\left(\Delta \mathrm{H}^{2+}, \Delta \mathrm{S}^{2+}\right.$, respectively), for the solvolysis of PNPA by poly-4(5)-vinylimidazole (2). The imidazole-catalyzed imidazole catalysis in a concentrated monomeric imidazole solution was previously observed during the solvolysis of p-nitrophenyl benzoates substituted by an electronwithdrawing group (4), and of $p$-substituted phenyl acetate substituted by an electrondonating group (5).

Two possible mechanisms were proposed $(2,6)$ which describe the interaction of two neutral imidazole pendent groups on the polymer chain with a substrate: (a) proton withdrawal from imidazole by another imidazole with a simultaneous catalytic solvolysis of the substrate by nucleophilic attack, as shown in (3), (b) a stepwise forma-

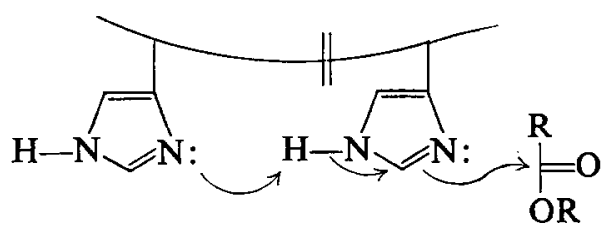

tion of a tetrahedral intermediate between the substrate and imidazole followed by a catalytic hydrolysis induced by another imidazole group, as shown in (4). A

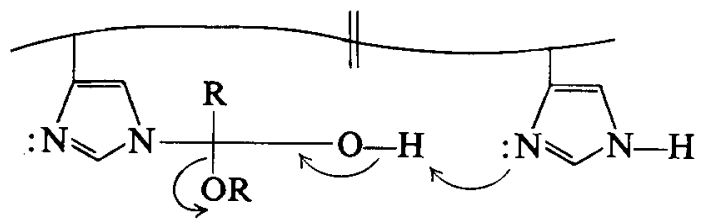

major purpose of this work was to determine the relative position and steric requirements between these two neutral imidazole residues on the polymer chain. Studies of the mechanism of action of chymotrypsin $(7)$ and ribonuclease $(8,9)$ indicated a longrange interaction between the catalytically active functional amino acid residues which are located quite far away from each other along the peptide chain (Nos. 57, 102, and 195 for $\alpha$-chymotrypsin and Nos. 12 and 119 for bovine ribonuclease A). These functional amino acid residues are brought in close proximity by the formation of a tertiary structure. On the other hand, the copolymer of 4(5)-vinylimidazole and p-methoxystyrene (with a mole ratio of ca. 1:2) did not affect the solvolysis rate of PNPA to any major extent (10), whereas the homopolymer of 4(5)-vinylimidazole catalyzed the solvolysis process to an appreciable extent. These results indicated that the long-range imidazole-imidazole interactions are probably not important during the solvolysis reaction. The short-range imidazole-imidazole interactions, which are specific and depend on the tacticity of the polymer, would therefore be the predominating factor.

If an imidazole-imidazole interaction involves two close imidazole groups (not necessarily adjacent), the solvolysis rate of PNPA, which is proportional to the probability of the imidazole-imidazole interactions, will increase with an increase of polymer molecular weight. The effect is self-limiting, however, since the contribution from remote imidazole will become negligible in a long polymer chain. On the other hand if this imidazole-imidazole interaction involves two imidazoles located far away from each other along the polymer chain, but which are held in close proximity by coiling 
of the chain, then the esterolytic rate of this polymeric catalyst should increase with an increase of molecular weight and would level off at a much higher molecular weight (II). Overberger et al. (10) have suggested that the spacing between interacting imidazole pairs can be varied by copolymerizing $4(5)$-vinylimidazole with another catalytically inert monomer in different molecular ratios. These copolymers could then be used to study the relationship between the solvolytic rate of PNPA and the distance between interacting imidazoles.

\section{EXPERIMENTAL}

\section{Oligomerizations}

Monomeric 4(5)-vinylimidazole (12), (3.0 g) (32 mmoles) and azo-bis-isobutyronitrile $(0.75 \mathrm{~g})$ ( 4.57 mmoles; 15 mole $\%$ of the monomer concentration) were dissolved in tetrahydrofuran $(70 \mathrm{ml})$ contained in a Pyrex glass tube. Nitrogen was then bubbled through the solution for $10 \mathrm{~min}$ before the tube was sealed. After being heated in a steam bath for $2 \mathrm{hr}$, with occasional shaking, the solution was poured into ether ( 2 liters) and the oligomers $(1.33 \mathrm{~g})$ were recovered by filtration. The oligomers were then dissolved in a small amount of methanol and reprecipitated by pouring into ether (1 liter), $1.07 \mathrm{~g}$. The combined filtrates were evaporated under reduced pressure, leaving a viscous oil $(2.2 \mathrm{~g})$ from which a further quantity of low molecular weight polymer $(1.2 \mathrm{~g})$ was obtained by removal of volatiles by heating at $102^{\circ}$ for $2 \mathrm{hr}$ and at $140^{\circ}$ for another $30 \mathrm{~min}$ under high vacuum. The total yield of crude low molecular weight polymer was $2.27 \mathrm{~g}$ (63\% conv.).

\section{Column-Packing Technique}

A glass tube, $3.5 \times 120 \mathrm{~cm}$, was fitted with a stopcock and a pressure head $(10 \times 20$ $\mathrm{cm}$ ) to facilitate packing (Fig. 1).

Sephadex LH-20 (200 g) (which had been swelled overnight in methanol) was employed.

To provide a flat bed for the filling, the base of the column was packed with glass wool and covered by a layer of $0.2-\mathrm{mm}$ glass beads topped by a circle of filter paper $(3.7 \mathrm{~cm}$ diameter). After one half of the column was filled with methanol, the swelled Sephadex LH-20 suspension was added all at once. To ensure tight, even packing, a stirrer connected to a low-speed, reversible motor (Colemen Palmer Co.) was lowered into the column. The direction of stirring was reversed every $30 \mathrm{sec}$. When a few centimeters of gel had settled, the stopcock was opened and 2 liters of methanol were passed through the column at a maximum flow rate. To complete the column preparation, the resin was washed overnight with a slow, continuous stream of methanol.

\section{Oligomer Fractionation}

Low molecular weight polymer $(0.6 \mathrm{~g})$, obtained by the procedure described earlier, was dissolved in methanol $(5 \mathrm{ml})$. The filtered solution was then added to the column and the solvent flow rate adjusted to $20 \mathrm{ml} / 20 \mathrm{~min}$. The effluent was collected in $20-\mathrm{ml}$ portions. The elution of the fractions was followed by uv absorption at $232 \mathrm{~m} \mu$. Removal of the solvent and drying of the residue at $100^{\circ}$ under reduced pressure gave the oligomer samples upon which the kinetic and molecular weight measurements were carried out. 


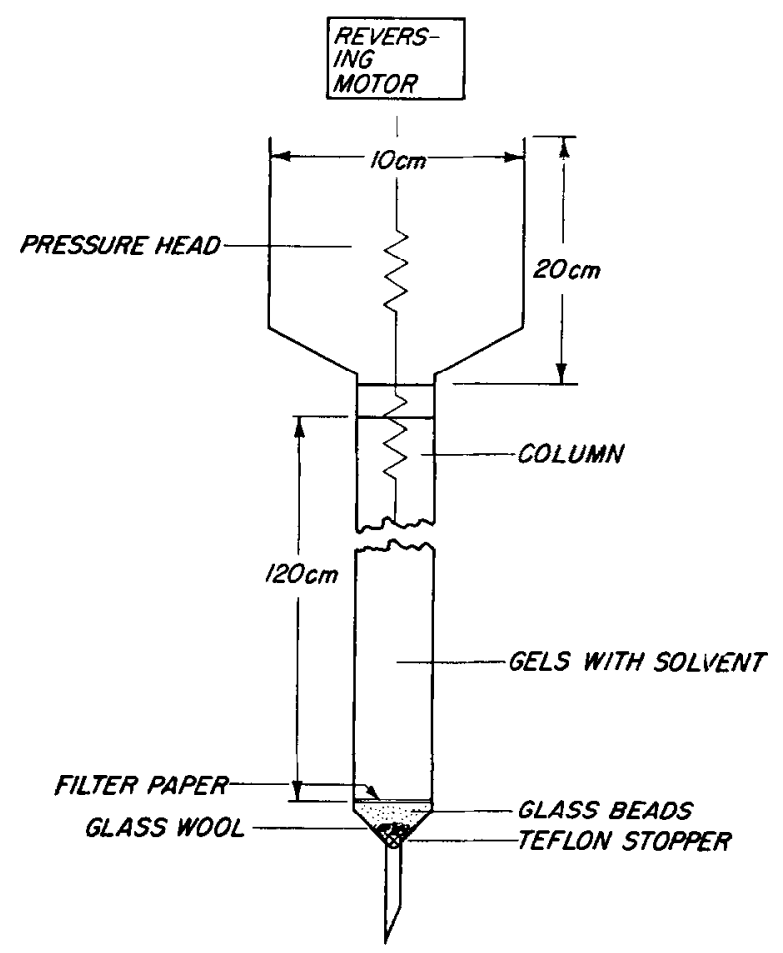

FIG. 1. Diagram of gel permeation chromatographic column with pressure head and stirrer.

\section{Molecular Weight Measurements}

A Hitachi-Perkin-Elmer Model-115 thermal-electric osmometer was used. A calibration curve was obtained using benzil as the standard. This standard curve was checked each time the instrument was used. Low molecular weight fractions, which have molecular weights under 1000 , were measured in $n$-propanol. The logarithm of the molecular weight of oligo-4(5)-vinylimidazole was plotted against the elution volume used for these oligomers. The straight line obtained for the first four oligomers was extrapolated to obtain the molecular weight of oligomers that were not completely soluble in $n$-propanol.

\section{Kinetic Measurements}

Stock solutions, ca. $5 \times 10^{-3} M$, were prepared by dissolving the oligomer (10-15 $\mathrm{mg})$ in $20 \%(\mathrm{v} / \mathrm{v}) n$-propanol-water $(25 \mathrm{ml})$. The concentration was calculated on the assumption that each oligomer had two isobutyronitrile end groups. Five-milliliter aliquots of these solutions were then diluted to $50 \mathrm{ml}$ with $20 \%(\mathrm{v} / \mathrm{v}) n$-propanol-water $(\mathrm{pH} 8.18)$ or $30 \%(\mathrm{v} / \mathrm{v}) n$-propanol-water ( $\mathrm{pH} 8.13$ ) containing tris-(hydroxymethylaminomethane- $\mathrm{HCl}$ ) buffer $(0.02 \mathrm{~N}$, ionic strength 0.05 by $\mathrm{KCl})$, to give the required catalyst solutions.

For each kinetic measurement, $3 \mathrm{ml}$ of the required catalyst solutions (ca. $5 \times 10^{-4}$ $M$ ) was treated with a suitable amount of substrate solution [for PNPA, $200 \mu 1$ of $30 \% n$-propanol-water solution; for $p$-nitrophenyl heptanoate (PNPH), $50 \mu$ l of pure $n$-propanol solution; for $p$-nitrophenyl palmitate (PNPP), $200 \mu$ l of pure $n$-propanol 
solution]; the final substrate concentration in the reaction mixture being ca. $5 \times 10^{-5}$ $M$. The solvolysis reaction was followed by monitoring the appearance of the $p$ nitrophenoxide ion at $400 \mathrm{~m} \mu$ in a spectrophotometer. All the data obtained demonstrated a first-order dependence on ester concentration. The pseudo-first-order rate constant $k_{\text {measd }}$ (with catalyst) and $k_{\text {blank }}$ (without catalyst), were treated by the expressions $k_{\text {obsd }}=k_{\text {measd }}-k_{\text {blank }}$ and $k_{\text {cat }}=k_{\text {obsd }} /[$ catalyst], where [catalyst] is the molar concentration of the imidazole functions.

\section{Substrate Preparations}

p-Nitrophenyl acetate. This compound, purchased from the Pierce Chemical Company, was sublimed in vacuo, $\mathrm{mp} 77.5-78.0^{\circ}\left(77.5-78.0^{\circ}(13), 79.5-80.0^{\circ}(14)\right)$.

p-Nitrophenyl heptanoate. This compound was prepared according to the method of Zahn and Schade (15), bp $132^{\circ} / 0.024 \mathrm{~mm}, n_{\mathrm{D}}^{25}=1.5122\left(160-162^{\circ} / 0.8(15)\right)$.

p-Nitrophenyl palmitate. This compound was obtained from $\mathrm{K} \& \mathrm{~K}$ Laboratories, Inc., $\mathrm{mp} 60.5-63.0^{\circ}\left(62-64^{\circ}(15)\right)$.

\section{Oligomer Titrations}

To prepare the oligomer titration solutions, $8 \mathrm{ml}$ of the stock solutions were added to $n$-propanol $(1.185 \mathrm{ml})$ containing $0.10 \mathrm{~N}$ sodium hydroxide- $\mathrm{KCl}$ solution $(100 \mu \mathrm{l})$ (this $\mathrm{NaOH}-\mathrm{KCl}$ solution was prepared by adding $745 \mathrm{mg}$ of KCl to a $50 \mathrm{ml}$ of $1.0 \mathrm{~N}$ sodium hydroxide). The resulting solution contained $n$-propanol $30 \%$ (by volume) and had an ionic strength of 0.003 . The titration with $0.5 \mathrm{~N} \mathrm{HCl}$ was carried out, with stirring, at $26^{\circ}$ in a water-jacketed cell using a micropipette and a Radiometer (type tttlc).

The glass electrode response was checked against two Beckmann buffer solutions. A blank titration curve was obtained by substituting $20 \%$ (v/v) aqueous propanol for the oligomer titration solution in the cell. Differential titration curves were derived graphically by the method of Park and Davis (16).

\section{RESULTS AND DISCUSSION}

\section{Oligomerization and Oligomer Fractionation}

A suitable low molecular weight poly-4(5)-vinylimidazole was obtained by a modified radical polymerization of 4(5)-vinylimidazole using a large amount of the radical initiator, azo-bis-isobutyronitrile, at an elevated temperature. Under these conditions, the initiator decomposed very rapidly forming a high concentration of primary radicals which, in turn, produced low molecular weight polymer by a high polymerization initiation rate and a high termination rate. Gel permeation chromatography (GPC) (17) is a separation technique (18) which fractionates molecules according to size. GPC on Sephadex LH-20, using methanol as solvent, fractionated low molecular weight poly-4(5)-vinylimidazole efficiently. Intermolecular hydrogen bonding between the imidazole groups on the polymer chain, which could interfere with the sharpness of the separation, should not occur in methanol solution since the molecular weight of monomeric imidazole, when measured in $n$-propanol, which is less polar than methanol, was normal. For good fractionation tight, uniform column packing is essential. To obtain such a packing, the solvent in the column was agitated by a stirrer whose 
rotation was alternated while the chromatographic gel was settling as recommended by Beling (19) and Rothstein (20). Fractionation was followed with a spectrophotometer at $232 \mathrm{~m} \mu$ using a short-path cell. A system yielding ca. 180,000 theoretical plates would be needed for complete resolution (21). Although this efficiency was not achieved, sharp peaks indicated that good resolution was obtained (Fig. 2).

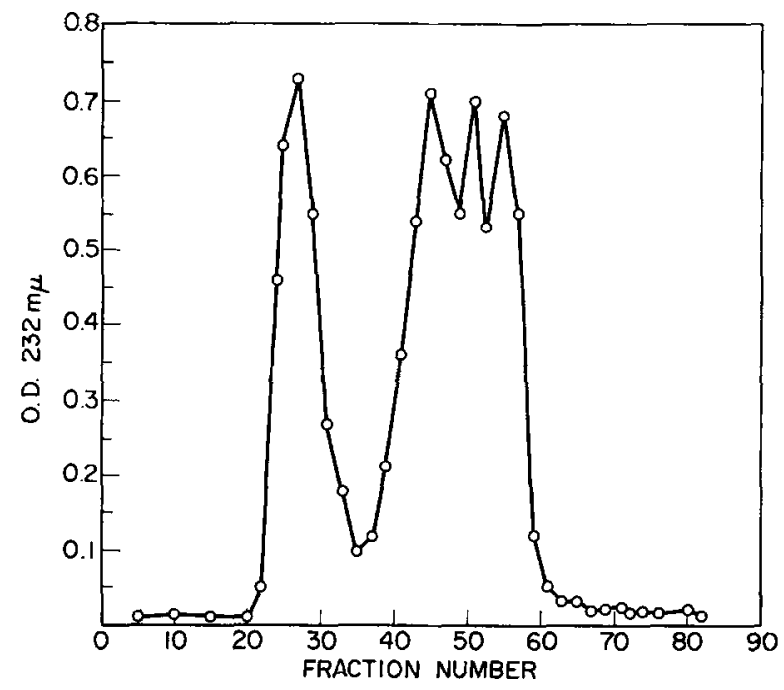

FIG. 2. Separation curve of the oligo-4(5)-vinylimidazoles.

\section{Oligomer Titration}

There is a remarkable difference between the apparent dissociation constant and titration curve of monomeric acids or bases and polyelectrolytes (22). When the hydrogen ion of the acid conjugated on a polymeric base dissociates, it will be repelled by the positive charges on the polycation. As a result, the polymeric base will become less and less basic as the polymer is progressively protonated. Because of this electrostatic effect, the well-known Henderson-Hesselbalch Eq. (5) is no longer valid for a

$$
\mathrm{pH}=\mathrm{p} K+\log \frac{\alpha}{1-\alpha}
$$

polyelectrolyte. Instead, a more generalized Eq. (6) should be used (22), where $n$ is

$$
\mathrm{pH}=\mathrm{p} K+n \log \frac{\alpha}{1-\alpha}
$$

no longer equal to unity. The deviation of $n$ from unity is usually related to the magniude of this electrostatic effect (23). For a polymeric acid, $\alpha$ is the fraction of acid dissociated. The plot of $\mathrm{pH}$ against $\log \alpha /(1-\alpha)$ gave a straight line in the range of $0.1<\alpha<0.9(22)$.

The oligomeric imidazoles were titrated in $30 \% n$-propanol-water in a constanttemperature cell, the temperature being maintained at $26^{\circ}$. Potassium chloride was added to keep the ionic strength of the titrated solution at 0.003 at the end point of each potentiometric titration. 
The generalized Henderson-Hesselbalch Eq. (6) was followed for oligomers at the "fraction of neutral imidazole $(\alpha)$ range" of 0.1 to 0.9 . These results are listed in Table 1 and Fig. 3.

TABLE 1

Results of Potentiometric Titrations of Pendent Imidazolium IONS IN OLIGO-4(5)-VINYLIMIDAZOLES

\begin{tabular}{lccc}
\hline \multicolumn{1}{c}{ Compound } & Molecular weight & $\mathrm{p} K_{\text {app }}$ & $n$ \\
\hline Imidazole & 68.04 & 6.6 & 1.07 \\
Oligomer 1 & 390 & 5.7 & 2.00 \\
Oligomer 2 & 492 & 5.6 & 2.04 \\
Oligomer 3 & 626 & 5.3 & 2.04 \\
Oligomer 4 & 914 & 5.2 & 2.61 \\
Oligomer 7 & $1820^{a}$ & 5.1 & 2.46 \\
Oligomer 8 & $2460^{a}$ & 5.1 & 2.28 \\
Poly-4(5)-vinylimidazole & $-{ }^{b}$ & 5.0 & 2.06 \\
\hline
\end{tabular}

a Determined by gel-permeation chromatography.

${ }^{b}$ This polymer was prepared by Dr. P. H. Vandewyer. The polymer has a specific viscosity of $0.44(0.5 \mathrm{~g} / \mathrm{dl})$ in methanol at $25^{\circ}$.

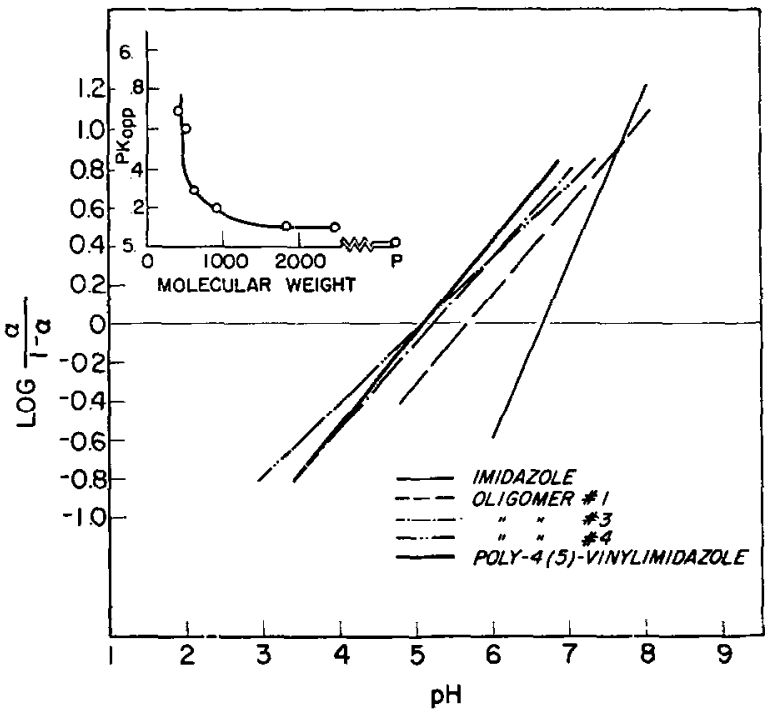

FIG. 3. Plot of $\log \frac{\alpha}{1-\alpha}$ vs. pH for the oligo-4(5)-vinylimidazoles. The change of apparent dissociation constant is plotted vs. the oligomer molecular weights in the insert.

Note that the apparent dissociation constant, $\mathrm{p} K_{\mathrm{app}}$, of the oligomers decreased rapidly as their molecular weight increased from 390 to 626. At molecular weights greater than 626 , the $\mathrm{p} K_{\mathrm{apD}}$ values level out. This is the first experimental conformation of the postulation that $\mathrm{p} K_{\text {app }}$ decreases with an increase of molecular weight, and becomes constant when the polymer reaches a certain molecular weight (23). The electrostatic force, which causes the variation of the apparent dissociation constant, 
is inversely proportional to the distance between two ionizable groups. This electrostatic effect is, therefore, significant only for ionizable groups in close proximity; for a remote ionizable group it is small to insignificant.

The value of $n$ in Eq. (6), which is related to the magnitude of the electrostatic effect, also increased with the molecular weight of the oligomer up to a maximum at 1000 . The $n$ values decrease upon further increase of molecular weight.

When the titration experiments were carried out at the same ionic strength $(0.05)$ used in our kinetic studies, the $\mathrm{p} K_{\mathrm{app}}$ value was found to be constant and independent of the molecular weight of the compounds. The oligomers and the polymer all have a $\mathrm{p} K_{\text {app }}$ value of 5.6.

\section{Kinetic Studies}

\section{The Solvolysis of p-Nitrophenyl Acetate}

Oligomeric-4(5)-vinylimidazoles with a molecular weight range of 400-2500 were used as catalysts for the solvolysis of PNPA in $29 \%(\mathrm{v} / \mathrm{v}) n$-propanol-water. The $\mathrm{pH}$ of the solution was buffered at 8.13 and $\mathrm{KCl}$ was added to keep the ionic strength at 0.05 . Since all the $\mathrm{p} K_{\mathrm{app}}$ values for the oligomers and the polymer are equal at this ionic strength, the apparent second-order rate constant, $k_{\text {cat }}$, was used directly as the parameter for the comparison. The results are shown in Table 2 and Fig. 4.

\section{TABLE 2}

APParent SECOND-Order Rate CONSTANTS For THE SOLVOLYSIS OF $p$-NITROPHENYL ACETATE IN $29 \%(\mathrm{v} / \mathrm{v})$ $n$-Propanol-Water at $26^{\circ}$, IONIC StREnGth 0.05

\begin{tabular}{lcc}
\hline \multicolumn{1}{c}{ Compound } & \multicolumn{2}{c}{$\begin{array}{c}k_{\text {cat }} \\
\text { (liter/mole min) }\end{array}$} \\
\hline Oligomer 1 & 390 & 6.06 \\
Oligomer 2 & 492 & 8.73 \\
Oligomer 3 & 626 & 10.52 \\
Oligomer 4 & 914 & 11.97 \\
Oligomer 7 & 1820 & 13.79 \\
Oligomer 8 & 2460 & 14.69 \\
Poly-4(5)-vinylimidazole & $-a$ & 16.14 \\
\hline
\end{tabular}

${ }^{a}[\eta]_{\mathrm{sp}}=0.44(0.5 \mathrm{~g} / \mathrm{dl})$ in methanol at $25^{\circ}$.

From Fig. 4, note that the efficiency of the polymeric catalyst increases with an increase of molecular weight. Imidazole groups in the oligomer of $\left\langle\mathrm{mol} \mathrm{wt} \mathrm{av}_{\mathrm{av}}\right\rangle 626$, which has ca. 5 imidazole units per oligomer molecule, showed $71 \%$ of the solvolytic rate shown by the oligomer with a $\left\langle\mathrm{mol} \mathrm{wt}_{\mathrm{av}}\right\rangle$ of 2460 . The terminal imidazole groups on the polymer chain will have neighboring imidazole groups on only one side of the polymer chain; therefore, they are less efficient in catalyzing the solvolysis of PNPA by a mechanism which requires two imidazole groups. Polymers with shorter chain lengths will be less efficient since a higher percentage of the total imidazole groups will occupy a terminal position. The fact that these low molecular weight oligomers are highly efficient in catalyzing the solvolysis of PNPA by an imidazole-catalyzed imidazole 


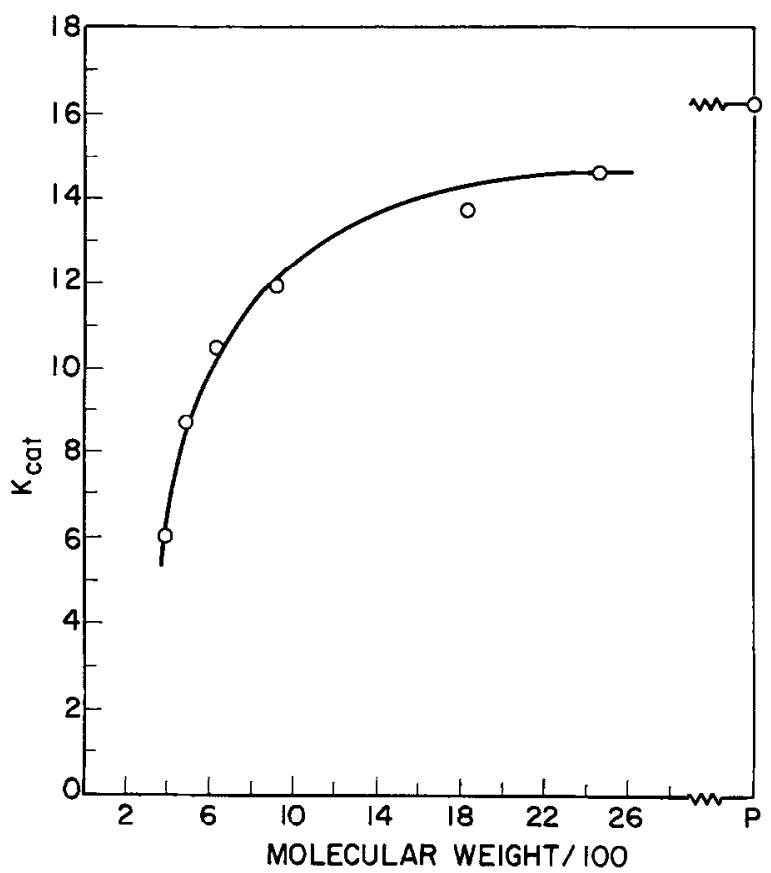

FIG. 4. Plot of second-order rate constants for the solvolysis of $p$-nitrophenyl acetate vs. the molecular weight of the oligo-4(5)-vinylimidazoles.

catalysis mechanism demonstrates the importance of short-range imidazole-imidazole interactions. $^{2}$

\section{Hydrophobic Interaction Between Oligomers and Long-Chain Substrate}

Hydrophobic forces are known to contribute to the association of nonpolar groups in aqueous solution, e.g., the maintenance of the tertiary structure of proteins and to the formation of enzyme-substrate complexes as a prelude to an enzymatic reaction

${ }^{2}$ There are many possible short-range interactions. Among them are 1,2, 1,3, and 1,4 imidazoleimidazole interactions as shown schematically below. For an oligomer with five imidazole units, we

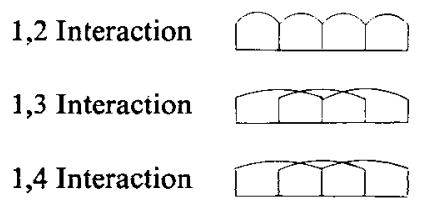

can see graphically that there are three possible 1,3 interactions; for an oligomer with 7 imidazole units there are five possible 1,3 interactions; for an oligomer with $n$ imidazole units the number of 1,3 interactions can be, therefore, generalized as $n-2$. A correction factor $n-2 / n$ should be used for oligomers with $n$ imidazole units. The correction factor for other possible modes of interaction such as 1,2 and 1,4 can also be derived in the same way. These factors should approach unity for a polymer with a very high molecular weight and decrease as the oligomer becomes smaller. If one minimizes the nucleophilic contribution of single imidazole groups as an approximation, one can calculate the solvolytic rate for an oligomer with $n$ imidazole units for each mode of imidazole-imidazole interaction, taking the solvolysis rate of PNPA catalyzed by high molecular weight poly-4(5)-vinylimidazole as a standard. The calculated values for 1,3 and 1,4 interactions approximate the experimental curve of $k_{\text {cat }}$ vs. molecular weight. 
(24). When most of the imidazole groups on poly-4(5)-vinylimidazole are in the neutral form, the oligomer is very sparingly soluble in water. It can, therefore, be regarded as hydrophobic. The interaction between 3-nitro-4-dodecanoyloxybenzoic acid (NDBA) and poly-4(5)-vinylimidazole was measured in solvents of various ethanol-water composition (25). The results indicate the hydrophobic nature of poly-4(5)-vinylimidazole in low alcohol-content aqueous solution.

An increase in the dimerization constant of alkyl carboxylic acids (26) and the linear increase in the effectiveness of the enzyme inhibitor 1-alkyl-3-aminocarbonylpyridinium chloride (27) as the chain lengths increase from $C_{1}$ to $C_{17}$ and $C_{3}$ to $C_{11}$, respectively, has also been explained in terms of increased hydrophobic interaction. It is possible, therefore, that the hydrophobic character of poly-4(5)-vinylimidazole will increase with increase of molecular weight. A series of imidazole oligomers with increasing molecular weight would provide a good model for assessing this possibility.

The solvolysis of $p$-nitrophenyl palmitate was carried out in $33.4 \%$ (v/v) $n$-propanolwater using the oligomer fractions as catalysts. The results have been listed in Table 3 .

TABLE 3

Solvolysis of $p$-Nitrophenyl Palmitate Catalyzed by OLIGO-4(5)-VINYLIMIDAZOLES IN $33.4 \%$ (v/v) $n$-PropaNOLWater at $26^{\circ}, \mathrm{pH} 8.13$, IONIC Strength 0.05

\begin{tabular}{lc}
\hline \multicolumn{1}{c}{ Compound } & $\begin{array}{c}k_{\text {cat }} \\
\text { (liter/mole min) }\end{array}$ \\
\hline Oligomer 1 & 2.07 \\
Oligomer 2 & 2.78 \\
Oligomer 3 & 2.74 \\
Oligomer 4 & 2.62 \\
Oligomer 7 & 2.14 \\
Oligomer 8 & 2.14 \\
Poly-4(5)-vinylimidazole & 2.30
\end{tabular}

TABLE 4

Solvolysis of $p$-Nitrophenyl Heptanoate Catalyzed by Oligo-4(5)viNyLimidazoles in AqueOus $n$-Propanol at $26^{\circ} \mathrm{pH}$ ca. 8 , IONIC STRENGTH 0.05

\begin{tabular}{|c|c|c|}
\hline \multirow[b]{2}{*}{ Compound } & \multicolumn{2}{|c|}{$k_{\text {cat }}($ litcr/mole $\mathrm{min})$ in } \\
\hline & $30.2 \% n-\mathrm{PrOH}-\mathrm{H}_{2} \mathrm{O}^{\circ}$ & $21.3 \% n-\mathrm{PrOH}-\mathrm{H}_{2} \mathrm{O}^{b}$ \\
\hline Oligomer 1 & - & 8.03 \\
\hline Oligomer 2 & - & 9.82 \\
\hline Oligomer 3 & - & 11.43 \\
\hline Oligomer 4 & - & 12.17 \\
\hline Oligomer 7 & 4.67 & 17.27 \\
\hline Oligomer 8 & 4.00 & 20.75 \\
\hline Poly-4(5)-vinylimidazole & 4.99 & 27.90 \\
\hline
\end{tabular}

${ }^{a} \mathrm{pH} 8.13$.

${ }^{b} \mathrm{pH} 8.18$. 
The rate constants were small in comparison with those values of PNPA's (Table 2). The catalytic rate constant was shown to be relatively insensitive to the molecular weight of the oligomer. An attempt to measure the solvolysis in low alcohol-content solutions was hampered by the low solubility of substrate in these solutions.

The solvolysis of $p$-nitrophenyl heptanoate by oligo-4(5)-vinylimidazole in $30.2 \%$ (v/v) $n$-propanol-water was observed at $26^{\circ}$. The catalytic rate constants are small and not much different from each other. A change in the reaction medium to $21.3 \%(\mathrm{v} / \mathrm{v})$ $n$-propanol-water produced an increase in the esterolytic rate of $p$-nitrophenyl heptanoate with an increase of the molecular weight of the oligomer as shown in Table 4. No leveling off of the esterolytic rate was observed. When the reaction temperature was raised from $26^{\circ}$ to $50^{\circ}$, the trend was comparable.

Alcohols are known to denature proteins by hydrophobic interaction, their order of efficiency as denaturing agents being $n-\mathrm{BuOH}>n-\mathrm{PrOH}>\mathrm{EtOH}>\mathrm{MeOH}$ (28). The kinetic results in Tables 3 and 4 show that in ca. $30 \%(\mathrm{v} / \mathrm{v}) n$-propanol-water solution, the solvolysis of the substrates proceeds at a minimal rate. In ca. $20 \%$ (v/v)n-propanolwater solution, the solvolysis of $p$-nitrophenyl heptanoate proceeds very rapidly. These results suggest that the catalytic activity of the oligomers is decreased in the presence of ca. $30 \% n$-propanol-water, presumably through a competitive hydrophobic interaction.

\section{ACKNOWLEDGMENT}

The authors are grateful for financial support by the National Institutes of Iealth under Grant GM-15256.

\section{REFERENCES}

1. C. G. Overberger, T. St. Pierre, N. Vorchheimer, J. Lee, and S. Yaroslavsky, J. Amer. Chem. Soc. 87, 296 (1965).

2. C. G. Overberger, T. St. Pierre, C. Yaroslavsky, and S. Yaroslavsky, J. Amer. Chem. Soc. 88, 1184 (1966).

3. (a) H. Walba and R. W. Isensee, J. Org. Chem. 21, 702 (1956); (b) T. C. Bruice and J. L. Herz, J. Amer. Chem. Soc. 86, 4109 (1964).

4. M. Caplow and W. P. JenCKs, Biochemistry 1, 883 (1962).

5. T. C. Bruice and S. J. Benkovic, J. Amer. Chem. Soc. 86, 418 (1964).

6. C. G. Overberger and J. C. Sal amone, Accounts Chem. Res. 2, 217 (1969).

7. D. M. Blow, J. J. BirkToff, AND B. S. HaRTley, Nature London 221, 337 (1969).

8. G. Kartha, J. Bello, AND D. Harker, Nature London 213, 862 (1967).

9. D. G. Smyth, W. H. Stein, and S. Moore, J. Biol. Chem. 238, 227 (1963); J. P. Cooke, C. B. ANfinsen, ANd M. Sela, J. Biol. Chem. 238, 2034 (1963).

10. C. G. Overberger, J. C. Salamone, and S. Yaroslavsky, J. Amer. Chem. Soc. 89, 6231 (1967),

11. H. MorAwetz, "Macromolecules in Solution," High Polymers, Vol. 21, p. 432. Wiley (Interscience), New York, 1965.

12. C. G. Overberger And N. Vorcheimer, J. Amer. Chem. Soc. 85, 95 (1963).

13. M. L. Bender and B. W. Turnquist, J. Amer. Chem. Soc. 79, 1652 (1957).

14. A. Kaufmann, Chem. Ber. 42, 3480 (1909).

15. H. ZahN AND F. Schade, Chem. Ber. 96, 1747 (1963).

16. T. V. Park And W. W. Davis, Anal. Chem. 26, 642 (1954).

17. H. Determann, "Gel Chromatograph; Gel Filtration, Gel Permeation, Molecular Sieves; a Laboratory Handbook," Springer-Verlag, New York, 1968.

18. M. J. R. CANTow, Ed., "Polymer Fractionation," Academic Press, New York, 1967.

19. C. G. Belling, Acta Endocrinol. Suppl. 79, 9 (1963).

20. F. RothsteIN, J. Chromatogr. 18, 36 (1965). 
21. K. J. Bombaugh, W. A. Dark, And R. F. Levangie, J. Chromatogr. Sci. 7, 42 (1969).

22. A. Katchalsky and P. Spitnik, J. Polym. Sci. 2, 432 (1947).

23. H. Morawetz, "Macromolecules in Solution," High Polymers, Vol. 21, p. 354. Wiley (Interscience), New York, 1965.

24. W. P. Jencks, "Catalysis in Chemistry and Enzymology," Chapt. 8. McGraw-Hill, New York, 1967.

25. C. G. Overberger, M. Morimoto, I. Cho, and J. C. Salamone, Macromolecules 2, 553 (1969).

26. E. E. Schrier, M. Pottle, ANd H. A. Scheraga, J. Amer. Chem. Soc. 86, 3444 (1964); P. MukerJEE, J. Phys. Chem. 69, 2821 (1965).

27. B. M. Anderson, M. L. Reynolds, And C. D. Anderson, Biochim. Biophys. Acta 99, 46 (1965).

28. E. E. Schrier, R. T. Ingwall, and H. A. Scheraga, J. Phys. Chem. 69, 298 (1965). 